\title{
Masonry wall panels retrofitted with thermal-insulating GFRP-reinforced jacketing
}

\author{
Antonio Borri · Marco Corradi • \\ Romina Sisti · Cinzia Buratti • \\ Elisa Belloni · Elisa Moretti
}

Received: 20 July 2015/ Accepted: 10 December 2015/Published online: 18 December 2015

(C) The Author(s) 2015. This article is published with open access at Springerlink.com

\begin{abstract}
Today there is a need to provide thermally efficient walls, while at the same time to increase the mechanical properties of old unreinforced masonry walls that will not require large amounts of energy in the retrofitting or deconstruction processes. To address this problem, this paper gives the results of shear tests carried out on masonry panels made of solid bricks retrofitted with a new technique based on the use of glass fiber-reinforced polymers (GFRP) grids inserted into a thermal insulating jacketing. This was made of different low-strength lime-based mortars. Tests were carried out in laboratory and results were used for the determination of the shear modulus and strength of the wall panels before and after the application of the GFRP reinforcement. Retrofitted panels exhibited a significant enhancement in the lateral capacity when compared to the control panels. The thermal performance of the proposed mortars was also investigated both with and without GFRP. Low values of thermal conductivity were found, especially for the samples
\end{abstract}

A. Borri - M. Corradi · R. Sisti - C. Buratti .

E. Belloni · E. Moretti

Department of Engineering, University of Perugia, Via

Duranti, 93, 06125 Perugia, Italy

M. Corradi $(\bowtie)$

Mechanical and Construction Engineering Department, Northumbria University Wynne-Jones Building,

NE1 8ST Newcastle upon Tyne, UK

e-mail: marco.corradi@northumbria.ac.uk with GFRP; a reduction of the thermal transmittance value in the $34-45 \%$ range was also obtained by applying $45 \mathrm{~mm}$ layer of coating in conventional masonry walls.

Keywords Masonry - Thermal insulating mortars · GFRP grids · Lateral loads · Testing

\section{List of symbols \\ Nomenclature \\ GFRP Glass Fiber Reinforced Polymers \\ $\gamma \quad$ Angular strain \\ $\lambda$ Thermal conductivity (W/mK) \\ $\sigma_{x y} \quad$ Shear stress (MPa) \\ $\tau \quad$ Masonry shear strength (MPa) \\ $f_{\mathrm{t}} \quad$ Masonry tensile strength (MPa) \\ $G \quad$ Masonry shear modulus (MPa) \\ $R \quad$ Thermal resistance $\left(\mathrm{m}^{2} \mathrm{~K} / \mathrm{W}\right)$ \\ $s \quad$ Thickness (m) \\ $U \quad$ Thermal transmittance $\left(\mathrm{W} / \mathrm{m}^{2} \mathrm{~K}\right)$}

\section{Subscripts \\ $c$ Coating \\ $p$ Plasterboard}

\section{Introduction}

Engineers and architects are often faced with the problem to increase the shear strength of historic 
unreinforced masonry (URM) walls. The poor quality of historic masonry is a factor of serious vulnerability that often makes difficult or impossible to design upgrading interventions in response to static and dynamic forces caused by earthquakes. The need to meet anti-seismic standards leads to the use of new reinforcement materials that are able to ensure an improvement of the mechanical properties of the walls. However this may cause the demolition of portions of buildings or the application of intrusive and non-reversible retrofitting techniques.

Following the destructive 1976 earthquake in northern Italy and Slovenia, technicians started studying the problem of conservation and upgrading of ordinary historic constructions. In the following years a series of new techniques were proposed and applied. Most of these are now regarded as "traditional" because they used standard materials like steel profiles and concrete. Surface treatments [1], grout injections [2-5], external reinforcements [6, 7] are examples of such conventional techniques.

Some of these strengthening techniques, such as steel jacketing and injections of cement- or lime-based grout, which were widely used in the reconstruction work following the earthquakes in the 80 s presented several negative issues over time in terms of effectiveness and durability $[8,9]$. The use of steel meshes embedded into cement-based mortars often leads to corrosion problems with loss of capacity and variation in volume and causes overstated increases of wall shear stiffness. The application of grout injection for stonewalls with no voids or cracks within the core makes this retrofitting intervention ineffective due to the impossibility for the grout to penetrate into the wall.

The most recent research studies have thus been directed towards different techniques, such as those which provide for bonding with composites materials (FRP: fiber reinforced polymers) [10-18]. Guidelines for the application of FRP materials to masonry were issued by the Italian founding research council (CNR) in 2003 [19]. Many advantages are associated with the use of FRPs, but their application is not entirely problem-free. Some drawbacks are attributed to the epoxy resins used to impregnate the reinforcing fibres: poor behavior at temperatures above the glass transition temperature and negative long-run effects, high cost of epoxy resins, potential hazards for the manual worker, difficulty in removal or irreversibility of the retrofitting intervention. The use of epoxy resins also prevents water-vapor permeability and its fire resistance is very low. In many cases heritage conservation authorities do not permit an extensive use of epoxy resins on listed buildings.

A promising solution to the above issues would be the replacement of epoxy resins with inorganic lime or cement mortars [20-22] to embed FRP bars or grids. The compatibility of inorganic matrices with historic masonry is extremely high: inorganic matrices, especially when lime-based, are similar in composition and mechanical properties to historic mortars.

However the need to insulate masonry walls, frequently the case in work done on historic-monumental buildings, greatly limits the choice of retrofitting methods. This is often needed for both relatively thin solid brick and thick stone walls. In a thick triple-leaf stone wall there are inner and outer leafs with a loose rubble fill between, almost a cavity wall and the inner surface is usually plastered with lime. Any increase in temperature in a stonework construction is lost very quickly because these walls work by allowing air to pass from inside to out.

The application of thermal insulating mortars is aimed to face the problem of energy consumption and represents an interesting solution to reduce heat loss in historic buildings. Thermal insulating mortars are usually cheap, easy to apply and compatible with historic mortars and bricks/stones. The replacement of steel meshes with composite materials embedded into thermal insulating mortars offers a solution to the problems typically faced in traditional steel meshes in concrete while the flexibility of this strengthening technique allows both indoor and outdoor applications, with different substrates (brick or stone work).

This paper presents the results of a series of tests on square wall panels reinforced with GFRP meshes embedded into lime-based mortars: both mechanical testing and thermal conductivity analyses have been performed to address the problem of the effectiveness of the proposed reinforcing technique.

\section{The strengthening technique}

The strengthening technique is very similar to the traditional steel jacketing for masonry wall panels: in place of a metal mesh, a GFRP grid is inserted into a thermal insulating mortar. Four different thermal 
insulating mortars have been used in this investigation. GFRP and thermal insulating mortars underwent a mechanical and thermal characterization.

GFRP grid used in the experimental campaign is produced by Fibre Net (Udine, Italy) and is made of a $66 \mathrm{~mm}$ square mesh fabricated with an AR (Alkali Resistant) glass fiber with a zirconium content greater than $16 \%$ impregnated with an epoxy-vinylester resin.

Before carrying out the present experimental investigation, the GFRP grid's mechanical properties were tested. The ultimate tensile strength of the impregnated roving constituting the grid are 530 and $680 \mathrm{MPa}$ in weft and warp directions, respectively. GFRP material exhibits a linear elastic response up to failure with a modulus of elasticity of 36.1 (weft dir.) and $39.8 \mathrm{GPa}$ (warp dir.). Strain at fracture is between 1.7 and $1.9 \%$ (Table 1 ).

The strengthening technique consists in the removal of all existing plaster back to the masonry (it is also possible to use a small cold chisel to remove any plaster left on the face of the masonry and to remove the loose pulverulent mortar from between the brick or stone blocks to a depth of $10-15 \mathrm{~mm}$ to increase the bonding between existing masonry and new coating). Before the application of the fist layer of thermal insulating mortar it is necessary to dampen the masonry by using a spray of clean water or flicking a brush. GFRP grid should be applied when the mortar is still wet. For multi-leaf walls (mainly stonemasonry).

GFRP transversal connectors can be used to bond masonry leaves. Each connector is made up of two fiberglass $L$ shaped bars joined together by injecting them with epoxy paste into a transversal hole drilled in the masonry wall. Lastly a second layer of the thermal insulating mortar can be applied by sprayer or hand in a thickness of about $50 \mathrm{~mm}$ (for a single-layer reinforcement the total thickness of the GFRP-reinforced coating is $100 \mathrm{~mm}$ ). Despite the presence of the GFRP grid, the application of thermal insulating mortar is not difficult, thanks to the large size of the meshes (Fig. 1).

The first thermal insulating mortar (Type RO, Röfix Calce Clima) is characterized by a compression strength of $0.7 \mathrm{MPa}$ according to the producer's data sheet. It is a ready-to-use hydraulic lime-based mortar with a small volume percentage of aerial lime, limestone sands and light mineral aggregates: it is light and completely natural.

The second mortar (Type D) is a hydraulic-based lime with the addition of granules of cork (diameter smaller than $0.3 \mathrm{~mm}$ ). It is on the market with the commercial name Diathonite Evolution and it is characterized by a compression strength of $2.7 \mathrm{MPa}$ according to the producer's data sheet. The producer of the second mortar is Diasen.

The third (Type R2) and fourth (Type C) mortars were specifically studied and supplied respectively by Röfix and CVR in order to achieve both high mechanical characteristics and good insulating properties. Also the mortar Type $\mathrm{C}$ is composed by lime, aggregates and other additives with high mechanical strength. The lightness of all the tested mortars contributes to obtain good thermal insulating properties.

All mortars are non-cement based and have been subjected to mechanical characterization $[23,24]$ and results expressed in terms of compressive strength
Table 1 GFRP grid mechanical properties

\begin{tabular}{lll}
\hline Horizontal direction (weft) & Tensile strength $(\mathrm{MPa})$ & 530 \\
& Sample size & 10 \\
& Cross section area $\left(\mathrm{mm}^{2}\right)$ & 7.29 \\
& Elongation at failure $(\%)$ & 1.73 \\
& Young's modulus $(\mathrm{GPa})$ & 36.1 \\
Vertical direction (warp) & Tensile strength $(\mathrm{MPa})$ & 680 \\
& Sample size & 10 \\
& Cross section area $\left(\mathrm{mm}^{2}\right)$ & 9.41 \\
& Elongation at failure $(\%)$ & 1.93 \\
Weight density & Young's modulus $(\mathrm{GPa})$ & 39.8 \\
Grid spacing (mm) & $\left(\mathrm{kg} / \mathrm{m}^{2}\right)$ & 0.5 \\
& $(\mathrm{~mm})$ & 66 \\
\hline
\end{tabular}

530 


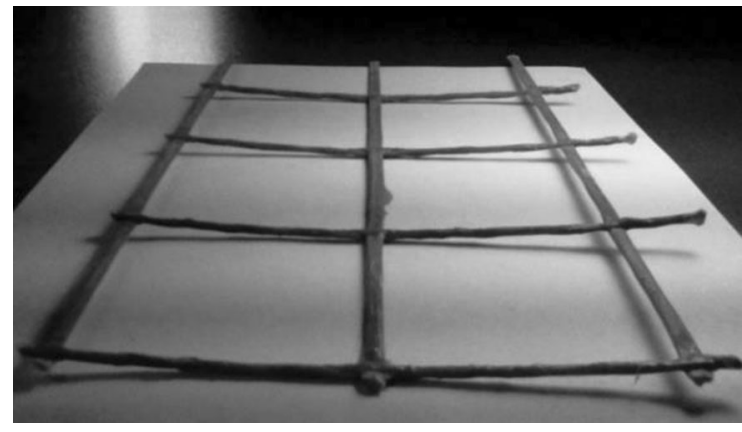

Fig. 1 GFRP grid

[25], tensile splitting strength [26], Young's modulus [27] are reported in Table 2. The choice of mortars with no-cement content was dictated by the need to meet the requirement of heritage bodies and to have good insulating properties. The mortars' mechanical properties were determined by compression and tensile splitting tests on cylindrical samples approximately $94 \mathrm{~mm}$ in diameter and approximately $180 \mathrm{~mm}$ in height. Compressive strength of mortar at 30 days after casting has been measured. Sixteen cylindrical samples (four for each type) were tested and the lowest and highest mean mortar strength was 0.72 and $2.70 \mathrm{MPa}$, respectively for mortars Type RO and $\mathrm{C}$.

The mechanical properties of the bricks and mortar used for the construction of the wall panels were also measured. The compressive and tensile splitting strength of mortar was obtained in laboratory and results are results are given as the mean strength value and coefficient of variation (Table 3 ).

Table 2 Properties of thermal insulating mortars

\begin{tabular}{lllll}
\hline Mortar designation & RO & D & R2 & C \\
\hline $\begin{array}{l}\text { Compressive } \\
\quad \text { strength (MPa) }\end{array}$ & 0.72 & 0.66 & 0.87 & 2.70 \\
Sample size & 4 & 4 & 4 & 4 \\
Coefficient of variation (\%) & 14 & 12 & 5 & 7 \\
$\quad$ Indirect tensile & 0.13 & 0.14 & 0.23 & 0.43 \\
$\quad$ strength (MPa) & & & & \\
Sample size & 4 & 4 & 4 & 4 \\
Coefficient of variation (\%) & 16 & 10 & 5 & 0.4 \\
$\quad$ Young's modulus (MPa) & 1130 & 580 & 1030 & 2396 \\
Sample size & 4 & 4 & 4 & 4 \\
Coefficient of variation (\%) & 24 & 16 & 11 & 15 \\
\hline
\end{tabular}

Table 3 Properties of bricks and mortar used for panel construction

\begin{tabular}{lll}
\hline & Mortar & Bricks \\
\hline Compressive strength (MPa) & 0.85 & 21.58 \\
Sample size & 19 & 10 \\
Coefficient of variation (\%) & 18 & 21 \\
Indirect tensile strength (MPa) & 0.18 & - \\
Sample size & 19 & - \\
Coefficient of variation (\%) & 31 & - \\
Young's modulus (MPa) & 12,640 & - \\
Sample size & 4 & - \\
Coefficient of variation (\%) & 21 & - \\
\hline
\end{tabular}

\section{Thermal performance of retrofitted masonry walls}

The thermal performance of the GFRP-reinforced mortars were experimentally evaluated by means of an experimental apparatus designed and built at the Laboratory of Thermal Science, University of Perugia (Small Hot-Box). It is composed by a hot and a cold side (with a difference of temperatures of about $20^{\circ} \mathrm{C}$ ) [28].

The thermal resistance of the mortars was evaluated by means of the thermal flux meter methodology consisting in the measurement of the heat flux through the sample and the surface temperatures in the cold and hot sides of the specimen. A typical trend of the surface air temperatures and of the heat flux during a test is represented in Fig. 2.

All the samples were assembled with external dimensions $300 \times 300 \mathrm{~mm}$, for a total area of $0.09 \mathrm{~m}^{2}$, due to the dimensions of the experimental apparatus. At first a specimen composed by only plasterboard without coating was tested (specimen PL) as support panel for the mortars. The coatings were analysed with different chemical compositions, with and without a glass fiber reinforced polymers grid, characterized by square mesh with dimensions of $60 \times 60 \mathrm{~mm}$, inserted into the matrix [29]. The description of the coatings, the total thicknesses of the specimens and the measured thermal resistances and conductivities of the composed samples (plasterboard + final coating) are reported in Table 4 . 
Fig. 2 Typical trends of surface temperatures and heat flux through a specimens during a test (duration approximately $4 \mathrm{~h})$

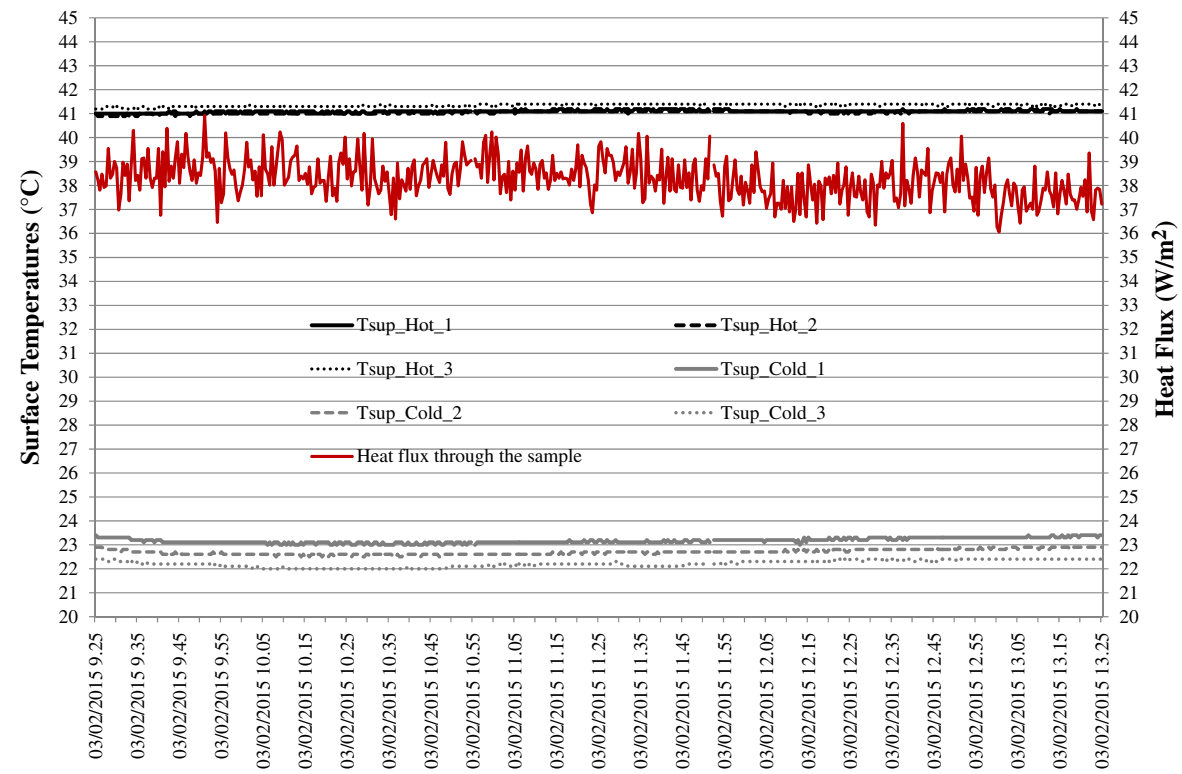

Table 4 Description of the samples for thermal measurements

\begin{tabular}{|c|c|c|c|c|c|c|c|}
\hline Samples & Description & $\begin{array}{l}s_{\mathrm{p}} \\
(\mathrm{mm})\end{array}$ & $\begin{array}{l}s_{\mathrm{c}} \\
(\mathrm{mm})\end{array}$ & $\begin{array}{l}s_{\text {total }} \\
(\mathrm{mm})\end{array}$ & $\begin{array}{l}\lambda_{\text {total }} \\
(\mathrm{W} / \mathrm{mK})\end{array}$ & $\begin{array}{l}\lambda_{\mathrm{c}} \\
(\mathrm{W} / \mathrm{mK})\end{array}$ & $\begin{array}{l}R \\
\left(\mathrm{~m}^{2} \mathrm{~K} / \mathrm{W}\right)\end{array}$ \\
\hline PL & Plasterboard sheet & 13 & - & 13 & 0.186 & - & 0.07 \\
\hline Mortar RO & $\begin{array}{l}\text { Plasterboard + mortar with natural lime, } \\
\text { limestone sand, aggregates }\end{array}$ & 13 & 43 & 56 & 0.117 & 0.105 & 0.48 \\
\hline Mortar D & $\begin{array}{l}\text { Plasterboard }+ \text { mortar with clay, cork and } \\
\text { natural lime }\end{array}$ & 13 & 42 & 55 & 0.117 & 0.105 & 0.47 \\
\hline Mortar RO-GFRP & $\begin{array}{l}\text { Plaster board }+ \text { mortar with natural lime, } \\
\text { limestone sand, aggregates with glass fiber } \\
\text { reinforced grid }\end{array}$ & 13 & 42 & 55 & 0.102 & 0.089 & 0.54 \\
\hline Mortar D-GFRP & $\begin{array}{l}\text { Plaster board }+ \text { mortar with clay, cork and } \\
\text { natural lime with glass fiber reinforced grid }\end{array}$ & 13 & 42 & 55 & 0.106 & 0.092 & 0.52 \\
\hline
\end{tabular}

The total thermal resistance $R$ of the sample is composed by two contributes: the coating and the plasterboard one (Eq. 1). By using this equation it is possible to evaluate only the thermal conductivity of the coatings $\lambda_{\mathrm{c}}$.

$R=\frac{s_{\mathrm{c}}}{\lambda_{\mathrm{c}}}+\frac{s_{\mathrm{p}}}{\lambda_{\mathrm{p}}}$

where $s_{\mathrm{c}}$ and $s_{\mathrm{p}}$ are the thicknesses of the coating and the plasterboard, respectively.

The measured thermal conductivity of the mortars (Types RO and D) is $0.105 \mathrm{~W} /(\mathrm{mK})$ (without fiber reinforced grid), while considering the glass fiber reinforced grid (RO-FRP and D-FRP), 0.089 and $0.092 \mathrm{~W} /(\mathrm{mK})$ were respectively found, with a reduction of about 15 and $12 \%$. Also mortar R2 and $\mathrm{C}$ were examined but the thermal insulating properties of these types are not so meaningful above all for mortar Type C $(0.096 \mathrm{~W} /(\mathrm{mK})$ was measured for R2FRP and $0.210 \mathrm{~W} /(\mathrm{mK})$ for C-FRP): for the sake of brevity only the mortar types D-FRP and RO-FRP were considered in the following final application analysis.

For an in-deep analysis, the thermal transmittance $U$ of typical masonry walls can be calculated [30, 31] before and after the refurbishment action, in order to evaluate the effectiveness of the application of the mortars. Two walls were considered: the first one is a brick wall internally and externally lime plastered (total wall thickness $s_{\text {total }}=0.33 \mathrm{~m}, U=1.61 \mathrm{~W} /$ 
$\left.\left(\mathrm{m}^{2} \mathrm{~K}\right)\right)$, the second one is a cavity masonry wall with a total thickness of $0.28 \mathrm{~m}$ and a $U$-value of $1.10 \mathrm{~W} /$ $\left(\mathrm{m}^{2} \mathrm{~K}\right)$.

As shown in Table 5, by applying $45 \mathrm{~mm}$ of the mortars types RO-FRP and D-FRP, the $U$ reductions of the walls vary within 34 and $45 \%$. Generally the $U$ decreasing is more evident when the original thermal transmittance of the wall is higher (wall type n.1).

\section{Mechanical testing}

\subsection{Test set-up}

In order to study the shear behavior of the wall panels reinforced with thermal insulating coatings, 10 wall panels were assembled in laboratory and then tested in diagonal tension. Diagonal tension test is being widely used by the research community to develop knowledge on in-plane behavior of masonry walls. Figure 3 illustrates the test setup. A compression load was applied diagonally through a $500 \mathrm{kN}$ capacity hydraulic jack mounted at the top edge and activated by a hand pump. Loading steel shoes were positioned on the panel's diagonally-opposite corners. Two steel ties connected the loading shoes and a digital pressure transducer was applied on the hydraulic jack to measure the magnitude of the diagonal compression load. Four inductive linear transducers (LVDT) were installed along the panel four diagonals on each face to

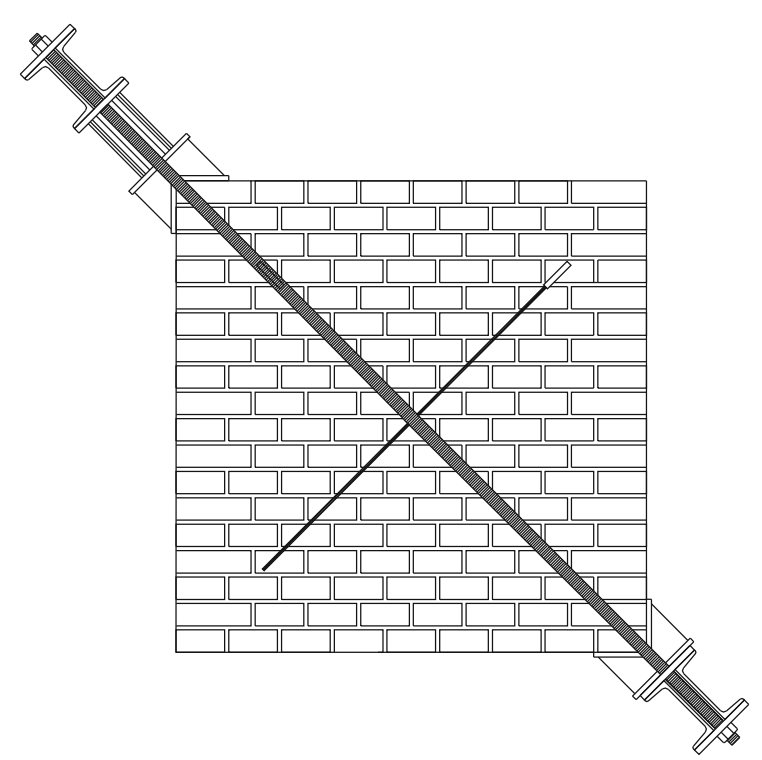

Fig. 3 Schematic arrangement of the test lay-out

measure its shortening and elongation. The diagonal compression load was applied in stepped cycles of loading and unloading using the manual pump, where the last cycle was continued till failure. All data were recorded by using a Spider8 data acquisition system operating Catman software at a frequency of $2 \mathrm{~Hz}$. Figure 4 shows the location of the instruments (LVDT, hydraulic jack, loading shoes) that was common to all specimens.

Diagonal tension test is standardized in accordance to ASTM [32] and RILEM [33] standards. In the test

Table 5 Thermal transmittance values of different walls before and after the insulating plasters application

\begin{tabular}{|c|c|c|c|c|c|c|}
\hline \multirow[t]{2}{*}{$\begin{array}{l}\text { Wall } \\
\text { type }\end{array}$} & \multirow[t]{2}{*}{ Description } & \multicolumn{2}{|c|}{$\begin{array}{l}\text { Before mortar } \\
\text { application }\end{array}$} & \multicolumn{3}{|c|}{ After mortar application } \\
\hline & & $\begin{array}{l}\text { Total } \\
\text { thickness } \\
s_{\text {total }}(\mathrm{m})\end{array}$ & $\begin{array}{l}U(\mathrm{~W} / \\
\left.\mathrm{m}^{2} \mathrm{~K}\right)\end{array}$ & $\begin{array}{l}U(\mathrm{~W} / \\
\left.\mathrm{m}^{2} \mathrm{~K}\right)\end{array}$ & $\begin{array}{l}\text { Total } \\
\text { thickness } \\
\text { (m) }\end{array}$ & $\begin{array}{l}U \text { reduction } \\
(\%)\end{array}$ \\
\hline 1 & $\begin{array}{l}\text { Brick wall }(s=0.3 \mathrm{~m}) \text {, internally and externally plastered } \\
\quad(t=15 \mathrm{~mm})(\mathrm{RO}-\mathrm{GFRP})\end{array}$ & 0.33 & 1.61 & 0.89 & 0.375 & 45 \\
\hline 2 & $\begin{array}{l}\text { Cavity wall }(s=0.25 \mathrm{~m}) \text { (hollow masonry blocks } 120+50 \mathrm{~mm} \text { air } \\
\text { gap }+ \text { hollow masonry blocks } 80 \mathrm{~mm}) \text {, internally and externally } \\
\text { plastered }(t=15 \mathrm{~mm})(\mathrm{RO}-\mathrm{GFRP})\end{array}$ & 0.28 & 1.10 & 0.71 & 0.325 & 35 \\
\hline 1 & $\begin{array}{l}\text { Brick wall }(s=0.3 \mathrm{~m}) \text { internally and externally plastered } \\
\quad(t=15 \mathrm{~mm})(\mathrm{D}-\mathrm{GFRP})\end{array}$ & 0.33 & 1.61 & 0.90 & 0.375 & 44 \\
\hline 2 & $\begin{array}{l}\text { Cavity wall }(s=0.25 \mathrm{~m}) \text { (hollow masonry blocks } 120+50 \mathrm{~mm} \text { air } \\
\text { gap }+ \text { hollow masonry blocks } 80 \mathrm{~mm}) \text {, internally and externally } \\
\text { plastered }(t=15 \mathrm{~mm})(\mathrm{D}-\mathrm{GFRP})\end{array}$ & 0.28 & 1.10 & 0.72 & 0.325 & 34 \\
\hline
\end{tabular}


setup according to ASTM, weight of the masonry wall is assumed to be disregarded compared to applied loads.

The RILEM interpretation of the test is based on a model of the masonry panel as if it is an isotropic and homogeneous material and a linear elastic analysis: the stress state in terms of normal $\left(\sigma_{x}\right.$ and $\left.\sigma_{y}\right)$ and shear stresses $\left(\sigma_{x y}\right)$ at the centre point of the panel:

$\sigma_{x}=\sigma_{y}=-0.56 \frac{P}{A_{n}} \quad \sigma_{x y}=1.05 \frac{P}{A_{n}}$

in which $P$ the diagonal compression load and $A_{n}$ is the cross- section of the wall panel, calculated as the average of the width and height of the specimen multiplied by its thickness. According to RILEM interpretation, the masonry tensile strength $f_{\mathrm{t}}$ is:

$f_{\mathrm{t}}=0.5 \frac{P}{A_{n}}$

According to the Turnšek and Čačovič [34] formulation, the shear strength $\tau$ is:

$\tau=\frac{f_{\mathrm{t}}}{1.5}$

Furthermore it is possible to calculate the shear modulus $G$ (secant value of the modulus at $40 \%$ of the peak load) defined as:

$G=\frac{\sigma_{x y, 0.4}-\sigma_{x y, i}}{\gamma_{0.4}-\gamma_{i}}$

where $\sigma_{x y, 0.4}$ and $\gamma_{0.4}$ are the shear stress at $40 \%$ maximum load and the angular strain at the corresponding strain value, respectively. The initial stress and strain $\left(\sigma_{x y, i}\right.$ and $\left.\gamma_{i}\right)$ were taken at a load level of $10 \%$ of the maximum diagonal load.

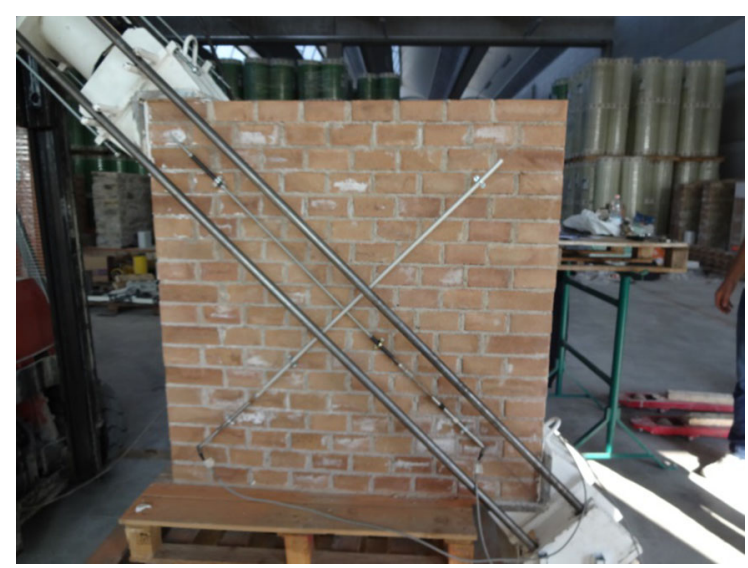

Fig. 4 Test apparatus arrangement
The angular strain $\gamma$ is expressed as:

$\gamma=\varepsilon_{\mathrm{c}}+\left|\varepsilon_{\mathrm{t}}\right|$

where $\varepsilon_{\mathrm{c}}$ and $\varepsilon_{\mathrm{t}}$ are the strains associated with the panel diagonals in compression and tension, respectively.

For both unreinforced and reinforced wall panels brickwork pattern was made from all headers (header bond pattern) on each course. Panels were assembled in laboratory using for construction a lime-based mortar. This bond pattern was chosen because it is frequently encountered in Italy for eighteen-nineteenth century constructions.

\section{Test results}

Although the resistance to in-plane forces is the key parameter to address the effectiveness of the proposed retrofitting technique, other factors such as the shear modulus, ductility and deformability, failure modes, stiffness and strength degradation from multi-cycle loading have been considered in this study. The different tests will hereafter be referred to by their number and letter designation. While the numerical designation will be different for each test, the letter designations indicate unreinforced panels (UR) and the type of mortar used for reinforcement (RO, D, R2 and C).

\subsection{Un-reinforced panels}

With regard to un-reinforced panels the shear stressangular strain curves show an initial quasi-elastic behavior followed by a nonlinear decrease in shear stress in the plastic region. The non-linear plastic behaviour of masonry response was produced by progressive diagonal cracking. In fact, all un-reinforced panels exhibited a failure along the compressed panel diagonal. Failure initiated in the central part of the wall panel when the diagonal compression force exceeded the in-plane strength capacity of the panel: diagonal cracking opened slowly in the mortar joints and expanded toward the panel extremities (corners) (Fig. 5). The failure produced and an abrupt loss of lateral stiffness (shear modulus). Two unreinforced brickwork panels have been tested and the average lateral capacity and shear strength $\tau$ were respectively $201.1 \mathrm{kN}$ and $0.230 \mathrm{MPa}$ while the shear modulus $G$ was $4078 \mathrm{MPa}$. Results are summarized in Table 6 and Fig. 6. 
Another point which needs to be mentioned is the low scattering of results in terms of shear strength (0.234 and 0.226 MPa for test No. 35-UR and 36-UR, respectively) and to some extent also for shear modulus (4466 and $3691 \mathrm{MPa}$ ).

\subsection{Reinforced panels}

Eight reinforced masonry panels were subjected to the diagonal tension test. For all reinforced panels, the masonry is initially uncracked and has a linear elastic response. A single test was performed on each wall panel. Table 6 gives peak lateral compression loads, shear strengths and moduli for each test.

For panels reinforced with mortar Type RO, the results obtained did not show significant increases both in terms of shear strength and stiffness. The lateral load-capacity and stiffness (shear modulus) values became, respectively $215.6 \mathrm{kN}$ and $4829 \mathrm{MPa}$ with a limited increment of 7 and $18.4 \%$ compared to the values measured for the control panels. This result substantially showed that the proposed technique is essentially ineffective when inappropriate thermal insulating mortars are used.

The stress-strain curve shows a quasi-elastic behaviour with a post-cracking pseudo-ductile response. Peak diagonal load was $247.5 \mathrm{kN}$ for panels reinforced using mortar Type D (33-D and 34-D). The results obtained for the diagonal tension tests carried out on the panel reinforced with this mortar showed a limited increase in terms of lateral capacity $(+23 \%)$ while the shear modulus $G(-0.6 \%)$ did not change.

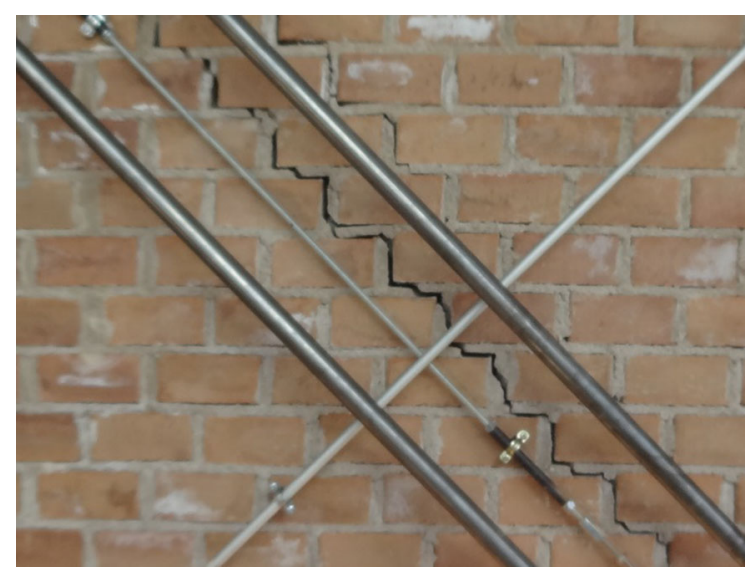

Fig. 5 Detail of failure (unreinforced panel)
Increases in strength (ultimate) from 57 to $62 \%$ and 109 to $115 \%$ compared with control panels were achieved for wall panels strengthened with GFRP reinforced mortars Type $\mathrm{R} 2$ and $\mathrm{C}$, respectively. Ultimate diagonal compression loads for these strengthened panels ranged from about 315 to $431 \mathrm{kN}$. Again the stiffness and deformation capacity of the wall panels was not highly changed by the application of the strengthening.

In-plane resistance of reinforced masonry wall panels is mainly based on tensile strength and stiffness of the thermal insulating mortars: mortar coatings have the function to transfer the tensile load from the substrate (masonry) to the GFRP grid reinforcement and to resist to compression loads. Low tensile strength mortars are unable to act on this issue leaving the reinforcement essentially unloaded and ineffective.

Figures 7 and 8 record the crack pattern in the masonry face for panels strengthened with GFRPreinforced mortars Type D and RO, respectively. For all reinforced panels, the failure modes are characterized by a similar cracking pattern as those of the unreinforced. The failure mechanism consisted in the formation of diagonal cracks along the compressed diagonal observed on mortar surface. Panels failed by rapid propagation of diagonal cracks, which followed the mortar joints and by separation of the GFRP coating from the masonry substrate. Tensile or shear failure of the strengthening never occurred in the GFRP grid, but failure by debonding initiating at the concentration of interfacial shear stress in the center of the panel and by the formation of diagonal cracks on the thermal insulating mortars.

Behavior of each reinforced specimen is illustrated in the shear stress versus angular strain plots shown in Fig. 9 (with the exception of test 38-R2 where angular strain was not recorded). From these results, a clear tendency is shown: the reinforcing technique can increase the lateral load-capacity of the masonry only if a thermal insulating mortar with good mechanical properties is used (compressive strength higher than 0.9-1.4 MPa, Young's Modulus higher than 1.1-1.3 $\mathrm{GPa}$ ). It is clear that these values depend on the mechanical properties of the substrate (masonry) and on the panel and coating thicknesses, but the emerging line seems to be correct and acceptable for standard one-brick-thick $(25 \mathrm{~cm})$ walls bonded with lime-based mortars hence allowing the considerations reported above. 
Table 6 Test results

\begin{tabular}{lllll}
\hline Test no. & Maximum diagonal load $P(\mathrm{kN})$ & Shear strength $\tau(\mathrm{MPa})$ & Load capacity increment $(\%)$ & Shear modulus $G(\mathrm{MPa})$ \\
\hline $35-\mathrm{UR}$ & 204.5 & 0.234 & - & 4466 \\
$36-\mathrm{UR}$ & 197.7 & 0.226 & - & 3691 \\
$31-\mathrm{RO}$ & 202.9 & $0.232^{*}$ & 0.8 & 4247 \\
$32-\mathrm{RO}$ & 228.3 & $0.261^{*}$ & 13.5 & 5412 \\
$33-\mathrm{D}$ & 236.4 & $0.271^{*}$ & 17.6 & 3981 \\
$34-\mathrm{D}$ & 258.5 & $0.296^{*}$ & 28.5 & 4127 \\
$37-\mathrm{R} 2$ & 315.6 & $0.361^{*}$ & 56.9 & 3528 \\
$38-\mathrm{R} 2$ & 325.5 & $0.373^{*}$ & 61.9 & - \\
$39-\mathrm{C}$ & 431.4 & $0.494^{*}$ & 115 & 3431 \\
$40-\mathrm{C}$ & 420.3 & $0.481^{*}$ & 109 & -
\end{tabular}

* Calculated using $250 \mathrm{~mm}$ panel thickness
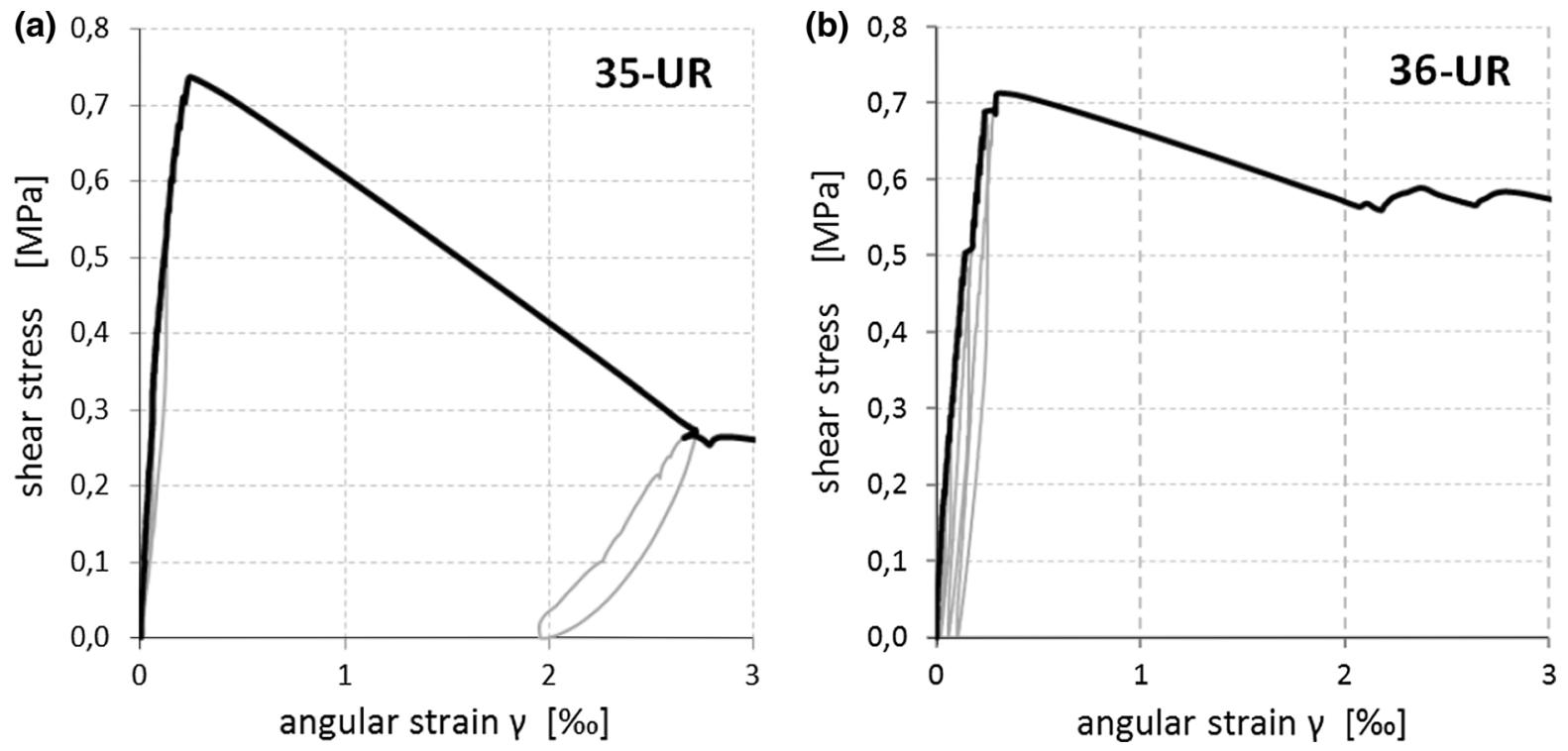

Fig. 6 Shear stress versu angular strain curves for unreinforced panels: a 35-UR, b 36-UR

For reinforced panels the diagrams underline two stages of the global behaviour: a first linear elastic and a second plastic produced by the progressive cracking of both the bed joint and coating reinforcing mortars. The post-cracking phase of the curves of the reinforced panels are characterized by reduced stiffness and a similar almost horizontal slope as those unreinforced. Thus, an important consequence of the reinforcement is the increase of the shear strength of the wall while leaving unaffected the in-plane stiffness.
The GFRP grid reinforcement is initially fully bonded and acts compositely with brickwork masonry. Since the shear stiffness is not significantly greater than for the unreinforced wall panels, the composite reinforcement does not at first increase the lateral diagonal compression load carried by the wall. For an angular strain of approximately $0.4 \%$, diagonal cracks form in the bed joints of the brickwork masonry and the GFRP grid start to work. This continues until the thermal insulating mortar starts cracking or to separate and debond from the masonry. 


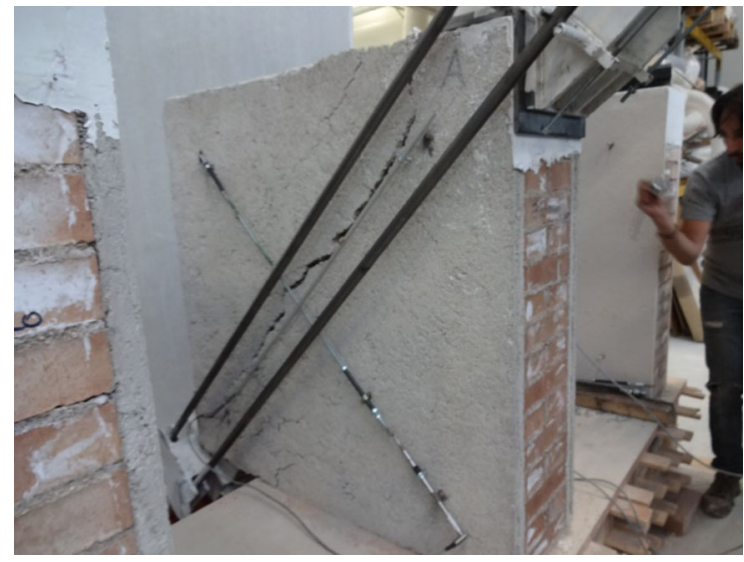

Fig. 7 Reinforced panel after failure (panel reinforced with mortar Type D)

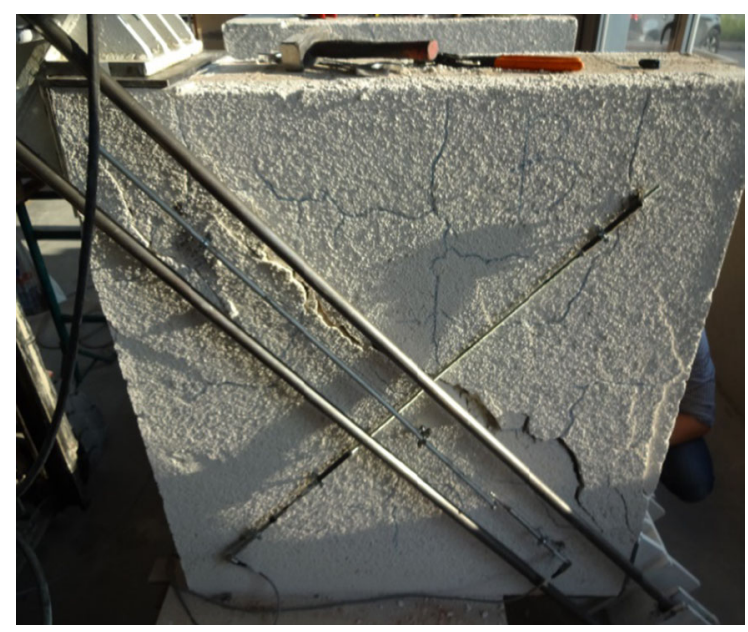

Fig. 8 Detail of the failure mode (panel reinforced with mortar Type RO)

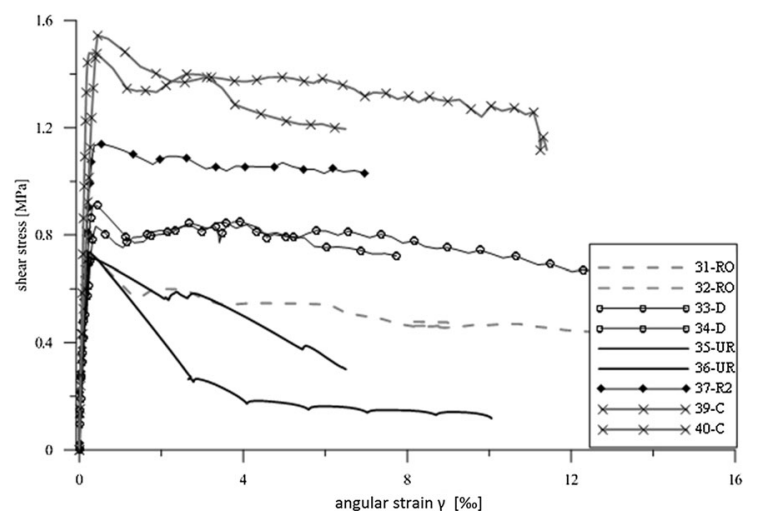

Fig. 9 Load-deflection response for all wall panels tested

\section{Conclusions}

Historic buildings with load bearing brick walls are very common in many European and American cities. While these thick brick walls are often plastered on one or both sides, they are usually not insulated and may present serious problems to resist to horizontal inplane loading produced by seismic actions.

This paper presents an experimental investigation on the behavior of in-plane loaded masonry panels retrofitted with an innovative method made of a GFRP grid inserted into a thermal insulating jacketing mortar. Four different thermal insulting mortars have been experimented and results have highlighted limitations and advantages of the proposed technique but in conclusion demonstrating the feasibility of using GFRP grids inserted into thermo-insulating mortars for both insulating and reinforcing masonry wall panels. The GFRP grid upgrade with thermal insulating mortar is promising, but less effective compared to the reinforcement with epoxy resins or steel reinforced concrete coatings $[4,6,9]$.

The following remarks may be drawn from this investigation:

1. The externally applied GFRP mesh to masonry panels resulted in a stronger system, as compared to the un-reinforced configuration. The addition of the GFRP grid embedded in thermal insulating mortars resulted in an increase in lateral load capacity between 7 and $117 \%$;

2. The reinforcing technique can increase the lateral load-capacity of the masonry only if a thermal insulating mortar with high mechanical properties is used (Types R2 and C);

3. The shear in-plane stiffness of reinforced panels remains essentially unaffected by the application of the reinforcement;

4. When low-strength lime-based thermal insulating coatings (Types RO and D) are used, the tests have highlighted the fact that the adhesion between the panels and the lime-based mortars used as a base for reinforcements (GFRP mesh) was the weakest element in the strengthening system. As the shear stiffnesses of the panel and reinforcement start to differ significantly due to diagonal cracking in the brickwork, the failure resulted from the separation of the layer of thermal insulating mortar from the masonry 
panels. This continues until the thermal insulating mortar also starts cracking.

5. The thermal performance of the innovative fiberreinforced insulating coatings were also studied. The thermal conductivities of samples RO and D were measured by thermal flux meter method by using an experimental Small Hot-Box apparatus. A similar behavior was found considering the thermal performance of only the coating without reinforced mesh $(\lambda=0.105 \mathrm{~W} /(\mathrm{mK}))$. The GFRP grid allows an improvement for both the samples (a reduction of the thermal conductivity of about $12-15 \%)$, probably due to air included in the mixture. Both the insulating coatings are efficient in building refurbishment also thanks to their thermal properties ( $U$-reduction of about $35-45 \%$ obtained by applying $45 \mathrm{~mm}$ of the coating).

Existing analytical formulations cannot fully explain tests results, based only on the variation of the type of thermal insulating mortar. Future work will concentrate on evaluating the accuracy for detecting the lateral capacity using innovative analytical and numerical assessments.

Acknowledgments This project was sponsored by the Italian Ministry of Education [ReLUIS (2014-2018), Research WP2 (Materiali Innovativi)]. Special thanks are directed to $\mathrm{Mr}$. Simone Tralascia. The authors would like to acknowledge Fibre Net S.r.l for financial support and material supply. Röfix and Diasen are also acknowledged for thermal mortar supply.

Open Access This article is distributed under the terms of the Creative Commons Attribution 4.0 International License (http:// creativecommons.org/licenses/by/4.0/), which permits unrestricted use, distribution, and reproduction in any medium, provided you give appropriate credit to the original author(s) and the source, provide a link to the Creative Commons license, and indicate if changes were made.

\section{References}

1. Corradi M, Tedeschi C, Binda L, Borri A (2008) Experimental evaluation of shear and compression strength of masonry wall before and after reinforcement: deep repointing. Constr Build Mater 22(4):463-472

2. Binda L, Modena C, Baronio G, Gelmi A (1994) Experimental qualification of injection admixtures used for repair and strengthening of stone masonry walls. In: Proceedings of the 10th international brick/block masonry conference, Calgary, Canada
3. Modena C (1994) Repair and upgrading techniques of unreinforced masonry structures utilized after the Friuli and Campania-Basilicata earthquake. Earthq Spectra 10(1):171-185

4. Corradi M, Borri A, Vignoli A (2002) Strengthening techniques tested on masonry structures struck by the UmbriaMarche earthquake of 1997-1998. Constr Build Mater 16:229-239

5. Valluzzi MR (2007) On the Vulnerability of historical masonry structures: analysis and mitigation. Mater Struct 40:723-743

6. Ashraf M, Khan AN, Naseer A, Ali Q, Alam B (2012) Seismic behavior of unreinforced and confined brick masonry walls before and after ferrocement overlay retrofitting. Int J Archit Herit 6:665-688

7. ElGawady M, Lestuzzi P, Badoux M (2004) A review of conventional seismic retrofitting techniques for URM. In: Proceddeing of 13th international brick and block masonry conference, Amsterdam, Netherlands

8. Binda L, Modena C, Baronio G, Abbaneo S (1997) Repair and investigation techniques for stone masonry walls. Constr Build Mater 11(3):133-142

9. Corradi M, Borri A, Vignoli A (2008) Experimental evaluation of the in-plane shear behaviour of masonry walls retrofitted using conventional and innovative methods. $\mathrm{J} \mathrm{Br}$ Mason Soc 21(1):29-42

10. Triantafillou TC (1998) Strengthening of masonry laminates using epoxy-bonded FRP laminates. J Compos Constr 2(2):96-104

11. Ehsani MR, Saadatmanesh H, Velazquez-Dimas JI (1999) Behavior of retrofitted URM walls under simulated earthquake loading. J Compos Constr 3(3):134-142

12. Borri A, Corradi M, Vignoli A (2002) New materials for strengthening and seismic upgrading interventions. In: Proceedings of 10th international workshop Ariadne, Check Republic, pp 22-28

13. Valluzzi MR, Tinazzi D, Modena C (2002) Shear behavior of masonry panels strengthened by FRP laminates. Constr Build Mater 16:409-416

14. Stratford T, Pascale G, Manfroni O, Bonfiglioli B (2004) Shear strengthening masonry panels with sheet glass-fiber reinforced polymer. J Compos Constr 8(5):434-443

15. Al-Salloum YA, Almusallam TH (2005) Walls strengthened with epoxy-bonded GFRP sheets. J Compos Mater 39:1719-1745

16. Santa Maria H, Alcaino P, Luders C (2006) Experimental response of masonry walls externally reinforced with carbon fiber fabrics. In: Proceedings of the 8th US national conference on earthquake engineering, paper no. 1402

17. Roca P, Araiza G (2010) Shear response of brick masonry small assemblages strengthened with bonded FRP laminates for in-plane reinforcement. Constr Build Mater 24: 1372-1384

18. Costa AA, Arêde A, Costa A, Oliveira CS (2011) In situ cyclic tests on existing stone masonry walls and strengthening solutions. Earthq Eng Struct Dynam 40:449-471

19. CNR DT200 (2004) Guide for the design and construction of externally bonded FRP systems for strengthening of existing structures. In: Technical document no. 200/2004, Italian National Research Council (CNR), Rome 
20. Borri A, Corradi M, Speranzini E, Giannantoni A (2010) Reinforcement of historic masonry with high strength steel cords. Mason Int 23(3):79-90

21. Papanicolaou CG, Triantafillou TC, Papathanasiou M, Karlos K (2008) Textile reinforced mortar (TRM) versus FRP as strengthening material of URM walls: out-of-plane cyclic loading. Mater Struct 41:143-157

22. Prota A, Marcari G, Fabbrocino G, Manfredi G, Aldea C (2006) Experimental in-plane behavior of tuff masonry strengthened with cementitious matrix-grid composites. J Compos Constr 10(3):223-233

23. ASTM C780-12a (2012) Standard test method for preconstruction and construction evaluation of mortars for plain and reinforced unit masonry

24. EN 12390-2 (2009) Testing hardened concrete-part 2: making and curing specimens for strength tests

25. EN 12390-3 (2009) Testing hardened concrete. Compressive strength of test specimens

26. EN 12390-6 (2009) Testing hardened concrete. Tensile splitting strength of test specimens

27. EN 12390-13 (2013) Testing hardened concrete. Determination of secant modulus of elasticity in compression

28. EN ISO 8990 (1996) Thermal insulation-determination of steadystate thermal transmission properties — calibrated and guarded hot box
29. Buratti C, Belloni E, Lunghi L, Borri A, Castori G, Corradi M (2015) Thermal conductivity measurements by means of a new 'Small Hot-Box' apparatus: innovative insulating reinforced coatings analysis

30. Buratti C, Moretti E, Belloni E, Agosti F (2014) Development of innovative aerogel based plasters: preliminary thermal and acoustic performance evaluation. Sustainability 6(9):5839-5852

31. Buratti C, Grignaffini S (2003) Measurement of the thermal resistance of masonry walls. Int J Heat Technol 21(2): 107-114

32. ASTM E519 (2002) Standard test method for diagonal tension (shear) in masonry assemblages

33. RILEM TC 76-LUM (1994) Diagonal tensile strength tests of small wall specimens. RILEM, recommendations for the testing and use of constructions materials. E\& FN SPON, London, pp 488-489

34. Turnšek V, Čačovič F (1970) Some experimental results on the strength of brick masonry walls. In: Proceedings of the 2nd international brick masonry conference, Stoke-onTrent, UK, pp 149-56 